\title{
Rock Fracturing under Pulsed Discharge Homenergic Water Shock Waves with Variable Characteristics and Combination Forms
}

\author{
Decun Bian $\left(\mathbb{D},{ }^{1}\right.$ Jinchang Zhao ${ }^{1 D},{ }^{1}$ Shaoqing Niu, ${ }^{1}$ and Jinwen $\mathrm{Wu}^{2}$ \\ ${ }^{1}$ Mining Engineering Institute, Taiyuan University of Technology, Taiyuan, China \\ ${ }^{2}$ College of Science, North University of China, Taiyuan, China
}

Correspondence should be addressed to Jinchang Zhao; zhaojinchang@tyut.edu.cn

Received 20 August 2017; Revised 17 February 2018; Accepted 5 March 2018; Published 22 April 2018

Academic Editor: Xinglin Lei

Copyright (C) 2018 Decun Bian et al. This is an open access article distributed under the Creative Commons Attribution License, which permits unrestricted use, distribution, and reproduction in any medium, provided the original work is properly cited.

\begin{abstract}
High voltage pulsed discharge in water (HVPD) is used throughout industry for fracturing both natural and man-made materials. Using HVPD, we modeled crack propagation of rocks under homenergic water shock waves (HWSW) with different characteristics and combination forms using a combination of experimental analysis and numerical simulation. The experimental results show that, under the same discharge energy $(2 \mathrm{~kJ})$, water shock waves (WSW) with different characteristics fractured the rock mass distinctly different. With a higher the peak pressure $\left(P_{P}\right)$ of WSW, more long cracks and microcracks were formed, creating a larger damage area. The numerical simulation results show that a single HWSWs impact with different characteristics will still only cause three long cracks to be well developed and almost no microcracks, when $P_{P}$ of HWSW was $3 \mathrm{MPa}$. With the increase of $P_{P}$, the number of both long cracks and microcracks increased. This is consistent with the experimental results. When the peak pressure became greater than $15 \mathrm{MPa}$, crack propagation gradually became concentrated and the surrounding borehole wall became more severely broken. The rock model had optimal fracturing under the impact of the HWSW with a $P_{P}$ of $10 \mathrm{MPa}$. Also, the simulations showed that, under repeated-impacts of HWSWs with consistent characteristics, the fracturing characteristics were basically identical to those by a single-impact. While under the repeated-impact of HWSWs with variable characteristics, there was almost no relationship between the fracturing effect and the sequence of repeated-impacts. Finally, under a single-impact of HWSW with low $P_{P}$ and hydrostatic pressure $\left(P_{H}\right)$ acting within an initial crack (similar to hydraulic fracturing in a hydrocarbon well), the initial crack had excellent propagation with an increase in hydrostatic pressure. However, when $P_{P}$ of HWSW was too high, increasing $P_{H}$ had no effect on initial crack propagation.
\end{abstract}

\section{Introduction}

High voltage pulsed discharge in water (HVPD) has primarily been used in the mineral industry, including but not limited to such practices as breaking down oil and gas wells [1], rock breaking and well drilling [2], and natural gas extraction [3]. The control, repeatability, and high stability of water shock wave (WSW) have great potential for industrial applications in the oil and gas industry for uses with oil and gas well break down and reservoir fracturing [4]. The studies in recent years found that the dynamic characteristics of WSWs produced by HVPD were influenced by many factors, including discharge voltage, capacitor value, discharge energy, electrode gap and type [5], and water conductivity [6]. There were significant differences in amplitude, frequency-domain characteristics, and energy spectrum of the WSWs when the discharge conditions were varied [7-9].

There have been several studies on the effects of HVPD on the rock fracturing process. During the process of loading repeated impulses on coal samples by HVPD, as the impact number increased, the microcrack line density increased [10]. Furthermore, as the impact number of HVPD increased, the coal pore structure improved, enhancing pore connectivity and overall permeability [11]. A single-impact with a higher WSW amplitude more clearly damaged the rock sample, and there was cumulative damage of the rock mass under repeated-impacts [12]. These studies greatly improved the understanding of HVPD on rock fracturing; however, they 
TABLE 1: High voltage pulsed discharge parameters table.

\begin{tabular}{lccccc}
\hline Group & Charging voltage $U$ & Capacitance $C$ & Discharging energy $E_{0}$ & Number of discharges & Number of specimens \\
\hline$\alpha$ & $8156 \mathrm{~V}$ & $60 \mathrm{uF}$ & $2 \mathrm{~kJ}$ & 1 & 2 \\
$\beta$ & $11547 \mathrm{~V}$ & $30 \mathrm{uF}$ & $2 \mathrm{~kJ}$ & 1 & 2 \\
\hline
\end{tabular}

did not consider the influence of WSWs' waveform characteristics, combination forms, and hydrostatic pressure $\left(P_{H}\right)$ on rock fracturing.

WSW as a type of dynamic load would show different loading characteristics due to the change of discharge conditions, and it has been shown that the dynamic response and characteristics of rock fracturing are not identical when WSW's loading characteristics are different. Cho and Kaneko found that a higher stress-loading rate of shock wave increases the number of radial cracks. The stress released from adjacent cracks affects crack extension and results in shorter crack propagation lengths. At lower stress-loading rates, the number of crack and crack arrest caused by stress released at adjacent cracks is reduced. This leads to greater crack extension [13]. However, their study does not unify the energy of WSWs which has different loading characteristics. Whether or not different characteristics of rock fracturing are caused by different WSWs' energy needs further study. In this paper, we studied the dynamic response and characteristics of rock fracturing under a single-impact and repeated-impacts of HWSWs. In addition, with $P_{H}$ affecting the initial crack, we also studied initial crack propagation under a single-impact. This research was accomplished through numerical simulation and single pulsed HVPD experiments on concrete, providing a theoretical basis for improving the technology principle of HVPD in rock fracturing, optimizing the effect of rock breakage and improving the working efficiency of oil and gas reservoir fracturing.

\section{The Experimental Principle}

2.1. The Principle of HVPD. HVPD is a very intense energy release process. Research findings showed that there is a close relationship between discharge form, WSW's characteristics, and discharge voltage, and capacitance of high voltage storage capacitor [14]. The energy $(E)$ stored in the storage capacitors can be determined by the formula (1):

$$
E=\frac{1}{2} C U^{2},
$$

where $C$ is the capacitance of energy storage capacitors and $U$ is the voltage of energy storage capacitors after charging.

The combination of different $U$ and $C$ also generates discharge breakdown processes with different characteristics, which then affect the characteristics of the WSWs, even when $E$ is constant. Two examples of WSWs generated by HVPD with different discharge parameters $(\alpha$ and $\beta$; for specific parameters, see Table 1) indicate that the waveforms of WSWs are indeed different when parameters are varied (Figure 1). This is because the electric potential difference at the electrode tips in the discharge process of the $\beta$ group is higher than that of the $\alpha$ group when $U_{\beta}>U_{\alpha}$. The speed of energy injection into the water by capacitors is higher in $\beta$ group, and the energy injected into the plasma channel per unit time increases. The plasma channel of the $\beta$ group is then able to achieve higher energy density before the channel wall expands; thus the plasma channel has higher temperature and pressure. However, because the energy stored by the capacitors is the same in both groups, high energy input density is bound to cause the inflation pressure duration of the $\beta$ group to be significantly shortened compared with to the $\alpha$ group. This causes the $\beta$ group to have a shorter duration of positive pressure (TDPP) and higher peak pressure $\left(P_{P}\right)$ in WSW's characteristics compared to the $\alpha$ group.

\subsection{The Principle of Fracturing by Dynamic Impact Loads.} Loading rate has an important role in the process of rock fracturing by dynamic impact loads. Common rock dynamic damage models show that, with an increase in loading rate, rock fragment size decreases, microcrack density increases, and number of macro long cracks decreases. When the WSW loading rate decreases, the rock fragmenting by dynamic impact load tends to gradually be static hydraulic fracturing [12]. This is mainly because the rock mass has different response characteristics under different dynamic impact loadings. Generally speaking, the dynamic strength of a rock mass increases with an increase in the loading rate of the dynamic impact load [15].

In addition, Kalthoff and Shockey [16] found that only when the time duration of the dynamic stress intensity factor exceeded material dynamic fracture toughness and was more than the required minimum duration for dynamic fracturing of a rock mass did cracks lose their stability and begin to extend. Even if the dynamic stress intensity factor of the crack tips was more than the dynamic fracture toughness of a rock mass, cracks did not necessarily extend, and it remains to be seen whether the time duration has a minimum duration needed for dynamic fracturing of rock mass.

Therefore, under a higher loading rate of a dynamic impact load, the rock mass appears to have a stronger dynamic strength, and TDPP is concurrently shortened. Thus, these phenomena make the expansion of macro long cracks more difficult, and much of the energy is dissipated in fractures, forming a large number of comminuted microcracks.

\section{The Experimental Equipment and Methods}

Single pulsed discharge rock fragmenting experiments were performed on four concrete samples using a custom made apparatus (Figure 2). The sand-binder ratio of the four concrete specimens was $10: 3$. The uniaxial tensile strength 


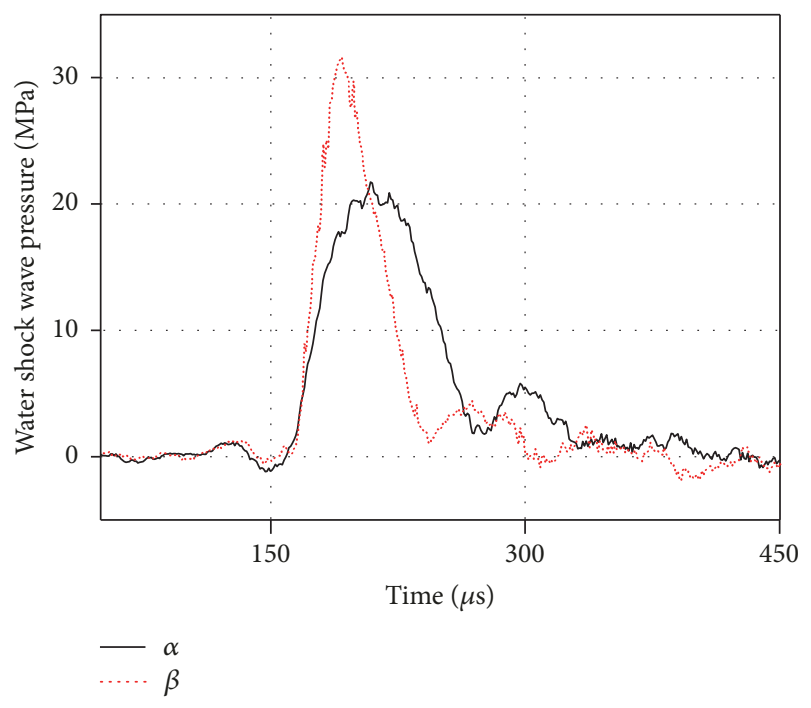

Figure 1: Pressure waveforms of WSWs in $\alpha$ and $\beta$ group.

and uniaxial compressive strength were $0.2 \mathrm{MPa}$ and $9.4 \mathrm{MPa}$. Before the start of the experiments, the original cracks in the concrete specimen were detected using a NM- $4 \mathrm{~b}$ nonmetal ultrasonic flaw detector. The plane transducer's frequency of the ultrasonic flaw detector was $50 \mathrm{KHz}$. Four specimen surfaces parallel to the axis of the borehole were arranged with 100 measuring points for each surface. After flaw detection, a specimen was placed on the test bench, electrodes were placed into a borehole filled with water, and the discharge ends of the electrodes were located in the center of specimen (Figure 2). After affixing and sealing the electrodes, the pulsed discharge cabinet and control box for charging operation were opened. Discharge parameters are shown in Table 1.

When charging was completed, a single pulsed discharge rock fragmenting experiment was carried out. After the discharge, the electrodes were removed and the water in the borehole was emptied. The cracks on the specimen surface were observed by a B008 handheld electronic microscope which has a 500x magnification, and the ultrasonic flaw detector then detected internal cracks in the specimen after the discharge.

\section{Experimental Data Analysis}

4.1. Morphology Analysis of Surface Cracks. Two groups ( $\alpha$ and $\beta$ ) of single HVPD rock fragmenting experiments were carried out on four concrete specimens. The surface cracks forms are shown in Figure 3.

The surface crack morphologies of the two samples were clearly different. There were more than three long penetrating cracks and several short nonpenetrating cracks in the $\beta$ group, with the long cracks apparently undergoing bifurcation. However, there were only two long penetrating cracks and no short nonpenetrating cracks in the $\alpha$ group, with no bifurcation of the long cracks.
4.2. The Ultrasonic Flaw Detection Analysis. In practical application, the more commonly used method of detecting internal cracks of a concrete specimen is to test the velocity variation of ultrasonic sound waves and use the velocity variation to indirectly represent the degree of rock damage.

The internal damage of the two groups of concrete specimens was significantly different (Figure 4). The long penetrating crack in the $\alpha$ group can be clearly observed (in the $X O Z$ plane), and the damage factor slightly increased near the detonation point. With this type of damage, there was basically no serious damage in the inner concrete specimens when the surface of the corresponding area had no cracks. Whether in the $X O Z$ plane or YOZ plane, the damage shown by ultrasonic flaw detection in the $\beta$ group was significantly greater than that in the $\alpha$ group, and a larger damage area was located near the detonation point area in the $\beta$ group compared to the $\alpha$ group.

Overall, $\beta$ group's rock fracturing was significantly greater than that of the $\alpha$ group. When $P_{P}$ was higher, the WSW was able to more effectively fracture the cement sample. When the discharge energy $(E)$ was invariant, it is unknown if the fracturing effect would continue to strengthen if we continued to improve the discharge voltage, as these experiments were limited by the capability of discharge experiment. Therefore, numerical simulation was used to study the effects of increased discharge voltage on rock fracturing.

\section{Numerical Simulations}

5.1. Establishment of a Discrete Element Model with Particle Flow Code (PFC). Before the Particle Flow Code (PFC) fracturing model was established, a standard specimen model was established using two-dimensional PFC (PFC2D). The uniaxial tensile strength (UTS) test and the uniaxial compressive strength (UCS) test were used select and verify the particle parameters in PFC2D. The final particle parameters are shown in Table 2. With those particle parameters, the standard specimen model's uniaxial tensile strength was $0.9 \mathrm{MPa}$ and the uniaxial compressive strength was 11 $\mathrm{MPa}$.

The WSWs was caused by the HVPD impact on the borehole wall directly as a form of pressure pulse. It was assumed that the expansion process of the plasma channel was spherical. To reduce the amount of calculation, the PFC fracturing model was simplified as two-dimensional plane model (Figure 5). Several unbonded particles were close to the borehole wall and were uniformly distributed as annular. These particles were used to simulate the WSWs' impact on the borehole wall. Seven gauge balls (numbers 1-7) were uniformly spaced between the hole wall and the model edge.

The experience formula for computing the energy of WSW is as follows [17]:

$$
E_{s}=\frac{S}{\rho v} \int_{0}^{+\infty} P^{2} d t
$$




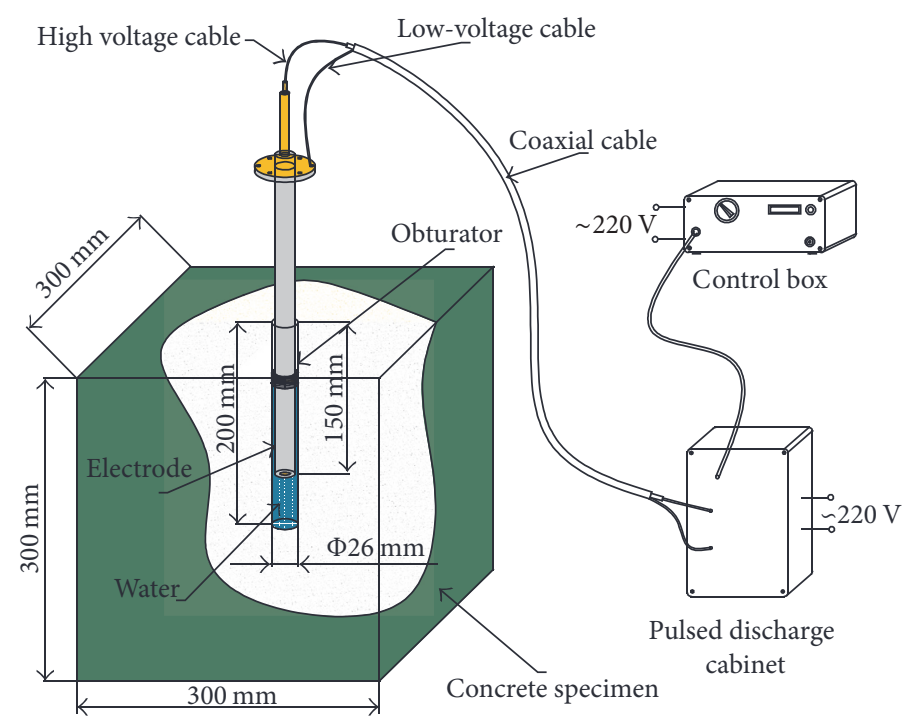

FIGURE 2: Diagram of experimental equipment.
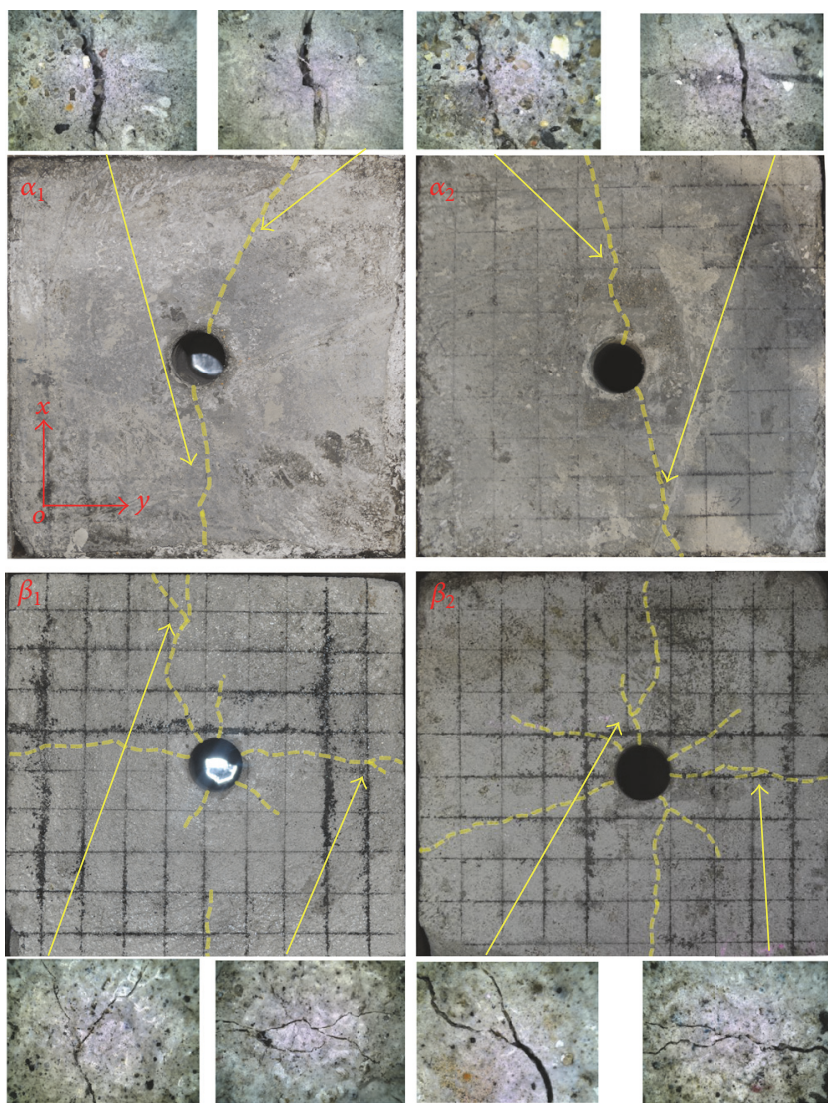

Figure 3: Photos of the surface cracks forms $\alpha$ and $\beta$ group.

where $E_{s}$ is the energy of WSW in J, $S$ is the wavefront area in $\mathrm{m}^{2}, \rho$ is the density of water in $\mathrm{kg} / \mathrm{m}^{3}, v$ is the velocity of WSW in $\mathrm{m} / \mathrm{s}$, and $P$ is the pressure of WSW in Pa.

Nine groups of homenergic WSWs (HWSWs) pressure time interval curves were built according to formula (2)
(Table 3). A part of those HWSWs pressure time interval curves is shown in Figure 6. Those nine groups of HWSWs had the same impact energy ( $35.6 \mathrm{~J}$ ), and those nine groups of HWSWs were placed into those unbonded particles. The model ran 1400 steps and each step length was $6.59723 \times$ $10^{-7} \mathrm{~s}$.

5.2. Crack Propagation under Single-Impact of HWSW. When the dynamic impact load was applied to the borehole wall, it provoked the corresponding stress wave in the PFC fracturing model (Figure 7). Cracks propagation of each group is shown in Figure 8.

The influence and propagation of cracks caused by the nine HWSWs groups were different (Figure 8). There were only three long cracks and no microcracks under the singleimpact of group I $\left(P_{P}: 3 \mathrm{MPa}\right)$. This is relatively similar to static hydraulic fracturing. With the increase of $P_{P}$ and decrease of TDPP, the number of long cracks increased and several microcracks appeared around the borehole. The variation from group I to III was consistent with the experimental results (group $\alpha$ to $\beta$ ). Due to the lower $P_{P}$ and longer TDPP, there were only two long cracks and almost no microcracks in group $\alpha$, and the damage surrounding the borehole was lower. This is similar to the fracturing of group I (three long cracks and no microcracks). With higher $P_{P}$ and shorter TDPP in group $\beta$, there were more than three long penetrating cracks and several short nonpenetrating cracks that appeared, and the long cracks that appeared underwent bifurcations. The damage around the borehole was larger than group $\alpha$. This is similar to the fracturing of groups II and III. Under the singleimpact of group III $\left(P_{P}: 10 \mathrm{MPa}\right)$, both long and microcracks were well developed, and the rock specimens had optimal fracturing. However, with increasing $P_{P}$ further, the amount and length of the long cracks started to decrease. In groups IV-IX $\left(P_{P}: 15-40 \mathrm{MPa}\right)$, the shape of the cracks was almost identical. No long cracks appeared and the distribution of 


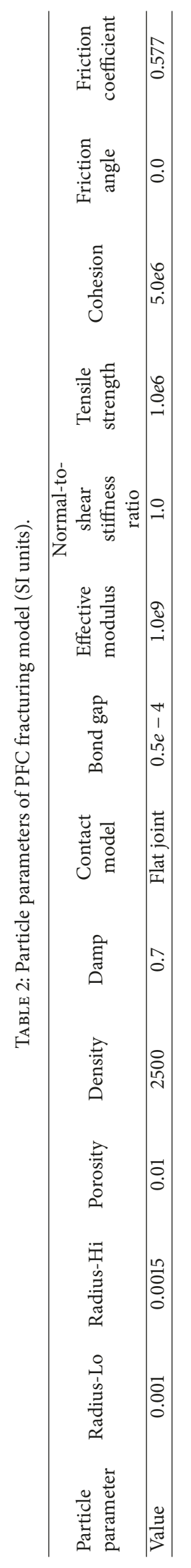




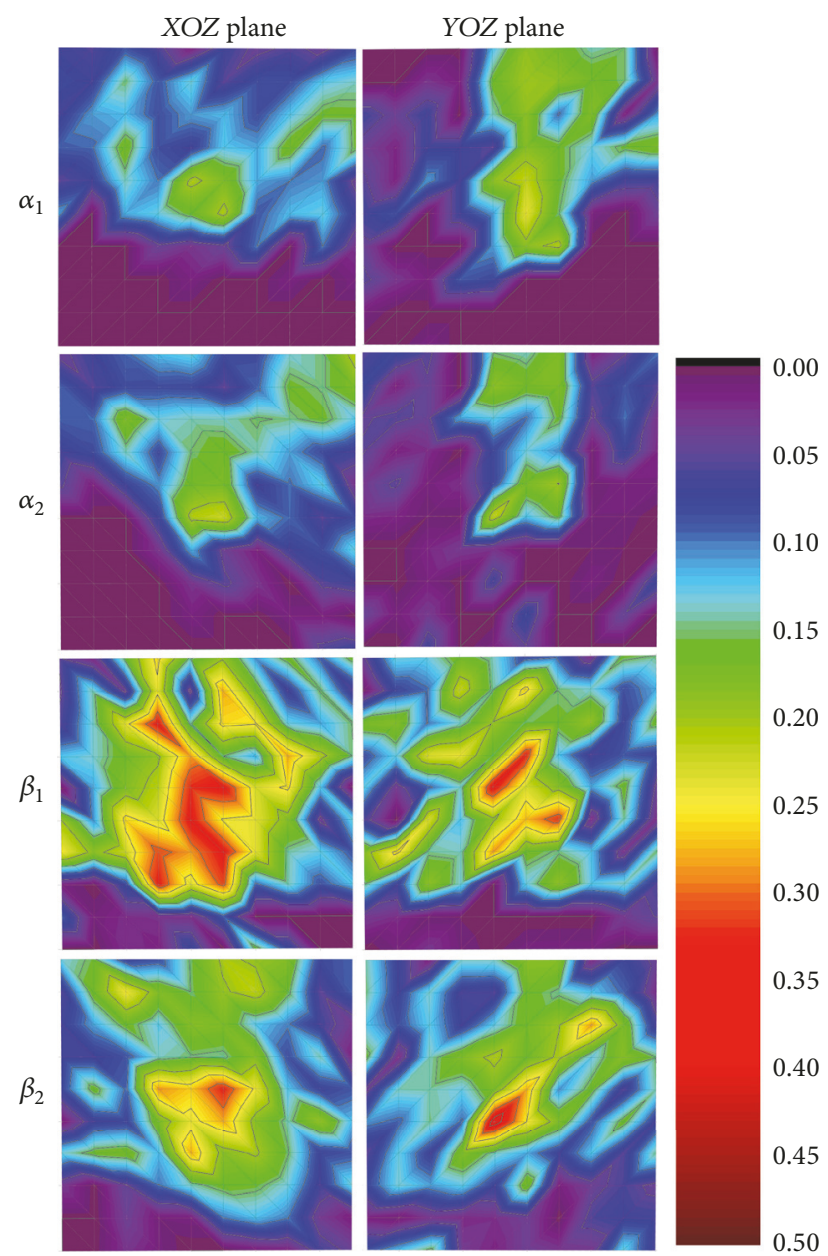

Figure 4: Distribution diagrams of damage factor in concrete specimens of groups $\alpha$ and $\beta$.

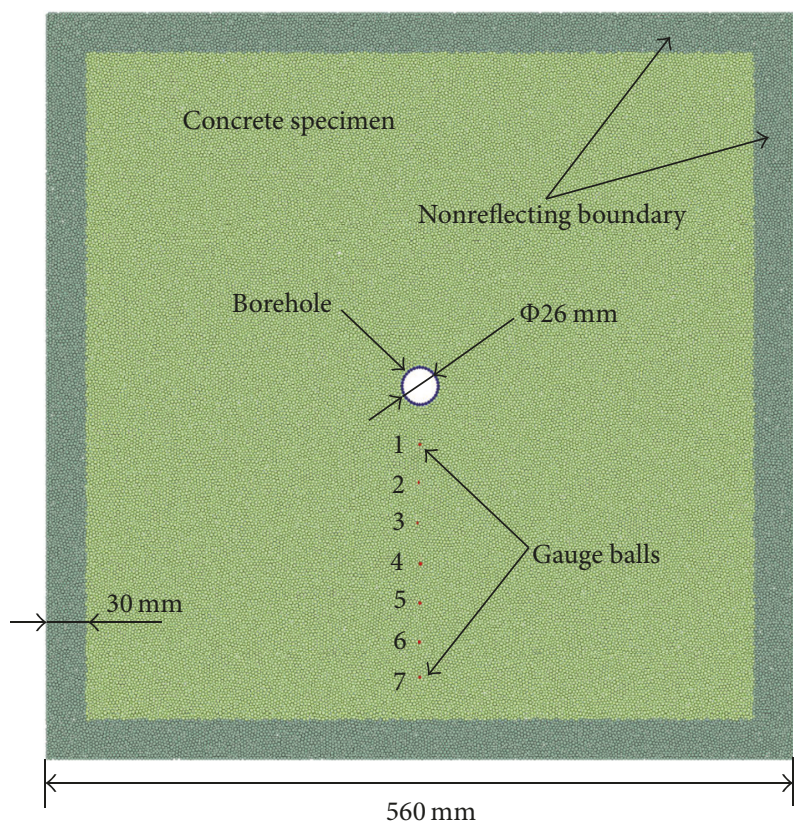

FIGURE 5: PFC fracturing model.
TABLE 3: Characteristics of nine groups HWSWs.

\begin{tabular}{lcccc}
\hline Group & $P_{P} / \mathrm{MPa}$ & $\mathrm{TDPP} / \mu \mathrm{s}$ & Loading rate $/ \mathrm{MPa} \cdot \mu \mathrm{s}^{-1}$ & Energy ratio \\
\hline I & 3 & 1140 & 0.011 & $100.59 \%$ \\
II & 5 & 408 & 0.049 & $100 \%$ \\
III & 10 & 102 & 0.417 & $100.03 \%$ \\
IV & 15 & 45 & 1.364 & $99.40 \%$ \\
V & 20 & 25 & 3.33 & $98.47 \%$ \\
VI & 25 & 16 & 6.25 & $99.06 \%$ \\
VII & 30 & 11 & 10 & $99.08 \%$ \\
VIII & 35 & 8 & 11.667 & $99.28 \%$ \\
IX & 40 & 6 & 20 & $100 \%$ \\
\hline
\end{tabular}

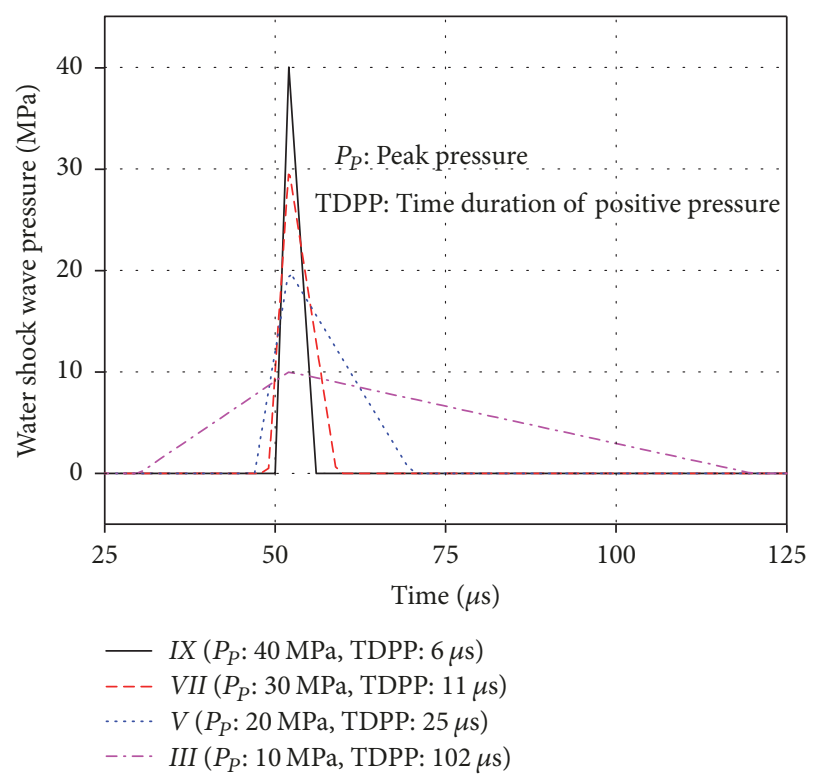

FIGURE 6: A part of HWSWs pressure time interval curves.

microcracks became more and more concentrated around the borehole. Furthermore, as the peak pressure increased from $3 \mathrm{MPa}$ to $40 \mathrm{MPa}$, rock fracturing augmented and then diminished slowly under a single-impact (Figure 9).

As the peak pressure increased from $3 \mathrm{MPa}$ to $10 \mathrm{MPa}$ (groups I to III), the vibration velocities at different distances were also enhanced (Figure 10). However, when the peak pressure increased from $20 \mathrm{MPa}$ to $40 \mathrm{MPa}$ (V to IX), the vibration velocity at different distances decreased. Within $75 \mathrm{~mm}$, the vibration velocity of group III with a singleimpact was smaller than that of groups IV IX. However, when the distance exceeded $175 \mathrm{~mm}$, group III had the largest vibration velocity. Namely, the stress wave in the PFC fracturing model caused by group III's single-impact had both strong vibrational velocity (compared with groups I and II) and weak vibration attenuation (compared with groups IV through IX), causing group III to have the optimal rock fracturing capability.

In conclusion, according to the impact energy (35.6 J) and the physical and mechanical properties of the PFC fracturing models in this article, the optimization waveform should have similar characteristics to group III. If the impact energy of 

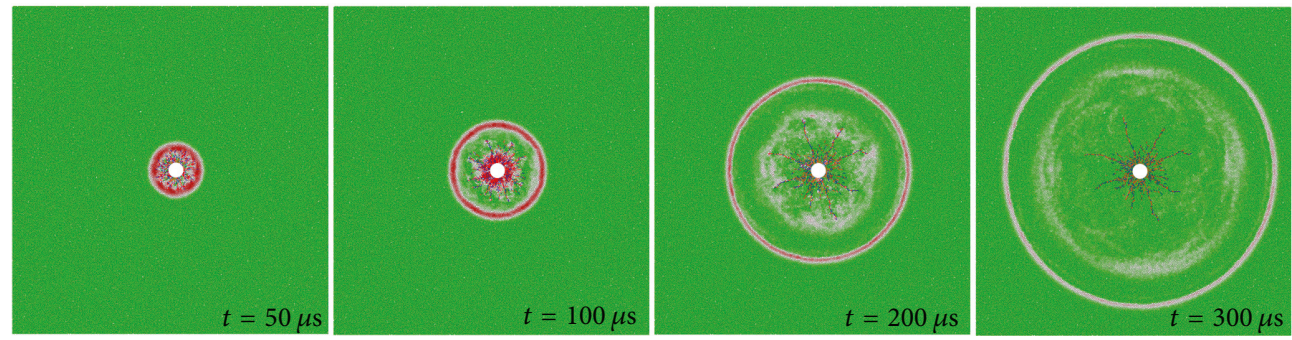

FIGURE 7: Transmission of stress waves.
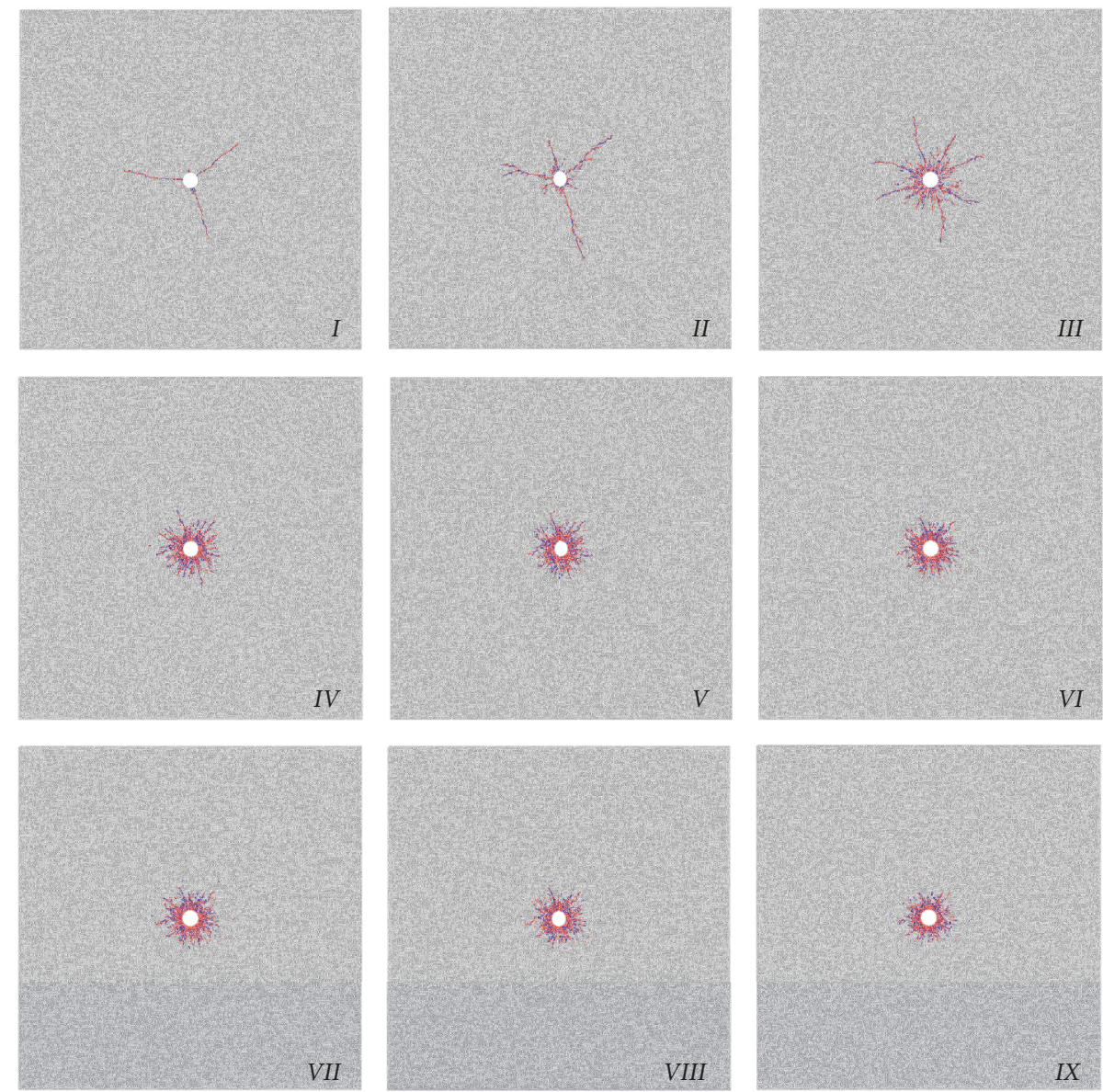

FIGURE 8: Crack propagation under a single-impact.

the WSW could not continue to improve, it is feasible and necessary to achieve a better fracturing and disturbance effect by optimizing the WSW waveform. For methane gas typically enriched in a reservoir in an adsorbed state, the better fracturing and disturbance effect could produce more methane gas migration channels and promote methane gas desorption. The optimization of the WSW waveform is mainly achieved by adjusting capacity and discharge voltage, and the above study provides a design basis for pulse discharge equipment for engineering application.

\subsection{Crack Propagation under Repeated-Impacts of HWSWs}

5.3.1. Crack Propagation under Repeated-Impacts of HWSWs with the Same Characteristics. Compared to the explosive impacts, the obvious advantage of impacts caused by HVPD is their repeatability within a short period of time. In order to study the fracturing effects of the repeated-impacts of HWSWs with same characteristics, three groups of pressure curves were chosen from the above model $\left(\mathrm{I}_{n}, \mathrm{III}_{n}\right.$, and $\left.\mathrm{IX}_{n}\right)$. Each group of those pressure curves was composed of $n$ times single-impact by the same corresponding HWSWs. These three groups were chosen because these three groups can achieve fracturing effects with more distinct characteristics.

The PFC fracturing models were impacted repeatedly until there were no further fractured Force-Chains appearing in the simulation. The long cracks of $\mathrm{I}_{n}$ and $\mathrm{III}_{n}$ extended further when compared with their single-impact counterpart from the previous section (groups I and III) (Figure 11). The repeated-impacts of the $\mathrm{IX}_{n}$ group, on the other hand, just 


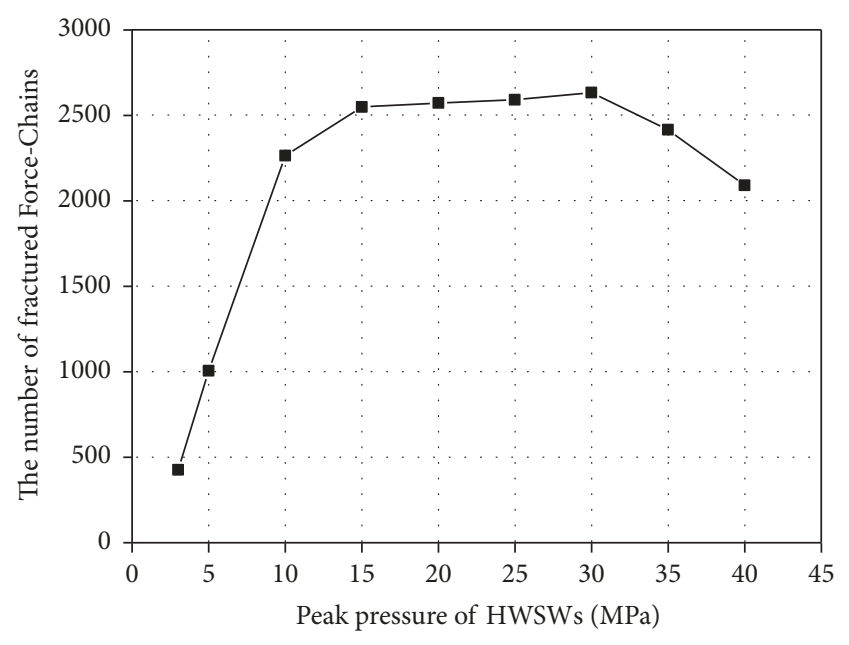

FIGURE 9: Number of fractured Force-Chains between two particles in PFC fracturing models under a single-impact for each of the nine groups (variable peak pressure).

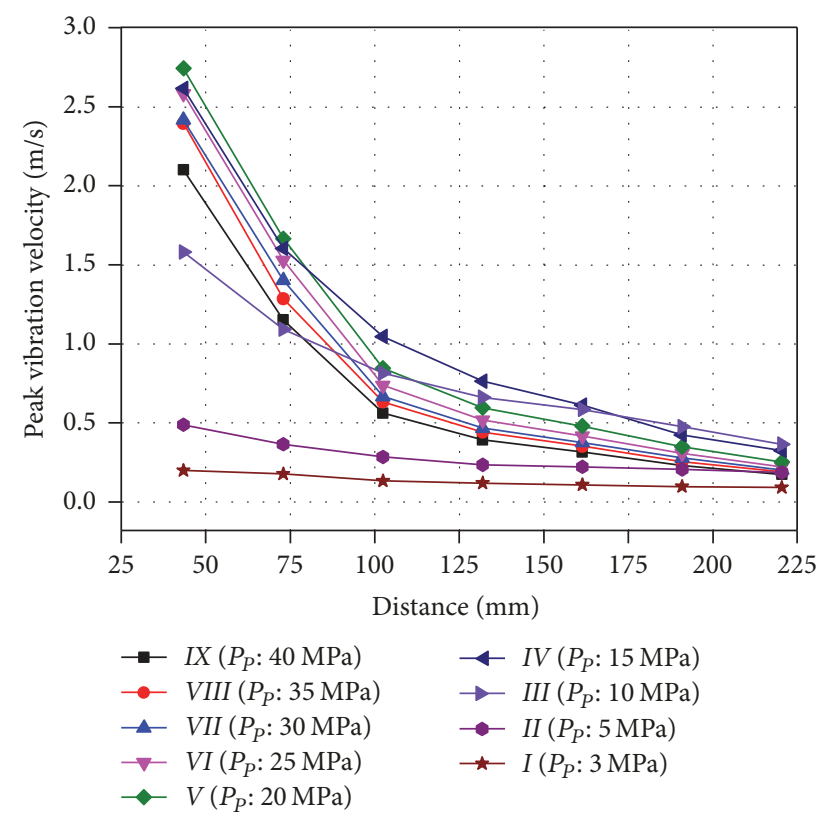

FIGURE 10: The vibration velocity attenuation curves under a singleimpact from the PFC fracturing models at variable distances from the center of the borehole for each of the nine used peak pressures.

increased the density of microcracks around the borehole wall and were almost no help for increasing crack propagation. On the whole, the characteristics of fracturing by groups $\mathrm{I}_{n}, \mathrm{III}_{n}$, and $\mathrm{IX}_{n}$ were basically the same as those by I, III, and IX. Repeated-impacts of HWSWs with same characteristics can strengthen the fracturing effect of a single-impact with a corresponding HWSW. When the number of impacts reached a certain number $\left(\mathrm{I}_{n}\right.$ group: 7 times, III $_{n}$ group: 15 times, and IX $_{n}$ group: 15 times), the cracks did not continue to expand (Figure 12).

5.3.2. Crack Propagation under Repeated-Impacts of HWSWs with Different Characteristics. Four groups of pressure curves were selected from the initial numerical simulation to study the effects of different characteristics of HWSW on crack propagation within a sample (groups $\mathrm{I}_{7} \mathrm{III}_{15} \mathrm{IX}_{15}, \mathrm{IX}_{15} \mathrm{III}_{15} \mathrm{I}_{7}$, $\langle\text { I-III-IX }\rangle_{12}$ and $\langle\text { IX-III-I }\rangle_{12}$ ) (Figure 13).

The final number of fractured Force-Chains (Figure 14) and crack propagation under four groups of repeated-impacts (Figure 15) was just slightly different. There were limits to the crack propagation in these four groups of repeated-impacts. This suggested that there is almost no relationship between the final fracturing effect and the sequence of repeatedimpacts. As long as the characteristics and impact times of repeated-impact were certain, no matter the sequence of these repeated-impacts, their final fracturing effects were almost the same.

5.4. Crack Propagation under a Single-Impact of HWSW with $P_{H}$ in the Initial Crack. Because oil and gas well fracturing is generally performed in shafts which are hundreds of meters deep, the water in the shaft must contain certain hydrostatic pressure $\left(P_{H}\right)$ when HVPD is implemented. Therefore, the PFC fracturing model with an initial crack in it was established. The distribution of the initial crack was horizontal and the length of it was $100 \mathrm{~mm}$. The maximum $P_{H}$ in the initial crack was $0.5 \mathrm{MPa}$ (if $P_{H}>0.5 \mathrm{MPa}$, initial crack would continue to expand under the effect of $P_{H}$ without any impact).

Under a single-impact in groups I and III, the greater the $P_{H}$ in the initial crack, the stronger effect on the initial crack extension (Figure 16). With the aid of $P_{H}$, the HWSWs can achieve a wider range of fracturing. In addition, under the single-impact of group III, with an increase in $P_{H}$, microcrack formation around the end of the initial crack (the end near the borehole wall) was inhibited. This would have a positive effect for maintaining the integrity of the borehole wall. However, under the single-impact of group IX $\left(P_{P}: 40 \mathrm{MPa}\right), P_{H}$ in the initial crack was almost no help for the propagation of the cracks and there was no inhibiting effect on microcrack formation around the borehole wall.

\section{Conclusions}

In this paper, using a combination of experiments and numerical simulation, we studied the dynamic response and characteristics of rock fracturing under a single-impact and repeated-impacts of HWSWs. In addition, with different hydrostatic pressures affecting the initial crack, we also studied initial crack propagation under a single-impact. The following can be concluded from this work:

(1) The characteristics of rock fracturing and vibration were different under single-impact HWSW (impact energy $=35.6 \mathrm{~J}$ ) with variable peak pressures. The characteristics of fracturing by the HWSW with a peak pressure $\left(P_{P}\right)$ of $3 \mathrm{MPa}$ (group I) tended to be static hydraulic fracturing: only three long cracks were well developed and there were no microcracks. With an increase in $P_{P}$ and decrease of TDPP, the number of both long cracks and microcracks increased (groups II, III). This is consistent with experimental results. However, when $P_{P}$ of HWSWs were greater than $15 \mathrm{MPa}$ 

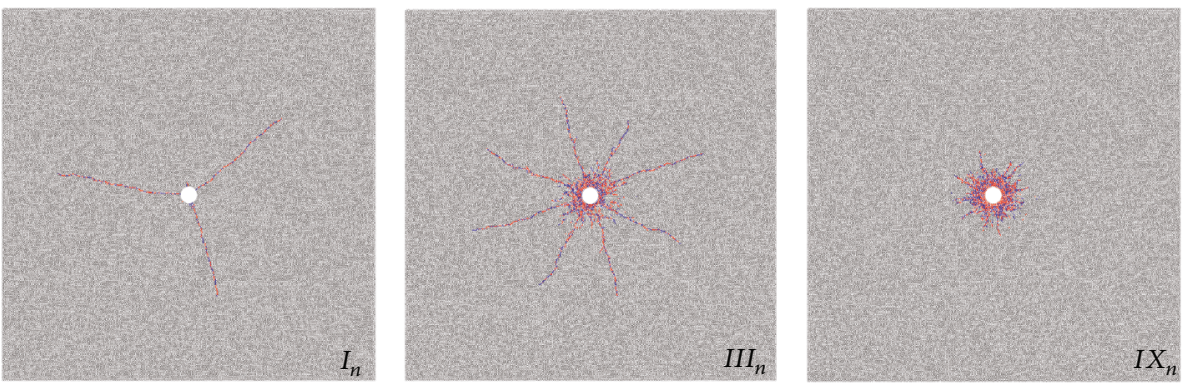

FIGURE 11: Crack propagation under repeated-impacts of HWSWs with same characteristics.

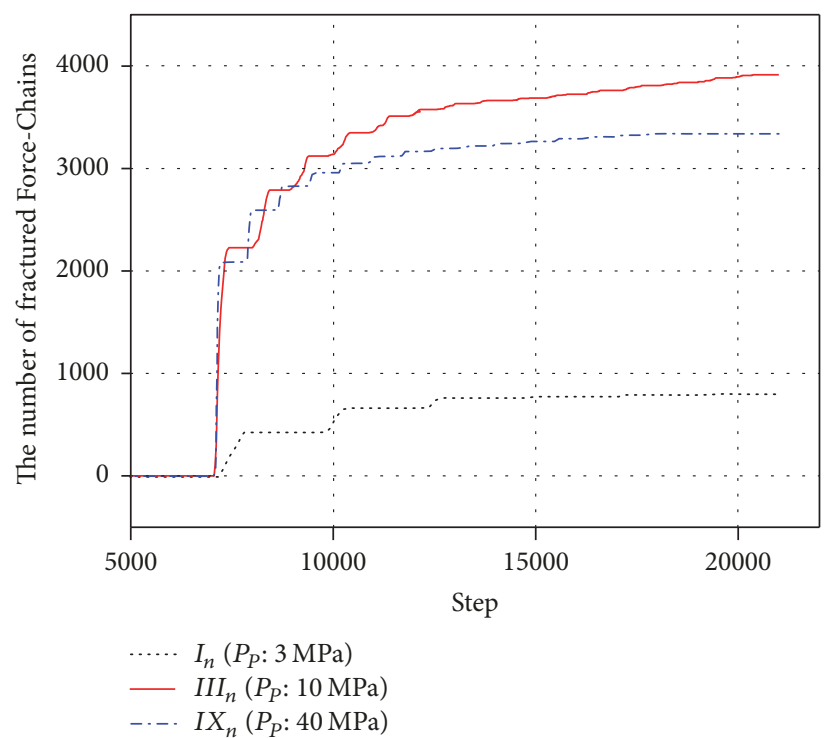

FIGURE 12: Growth curves of fractured Force-Chains under repeated-impacts of HWSWs.

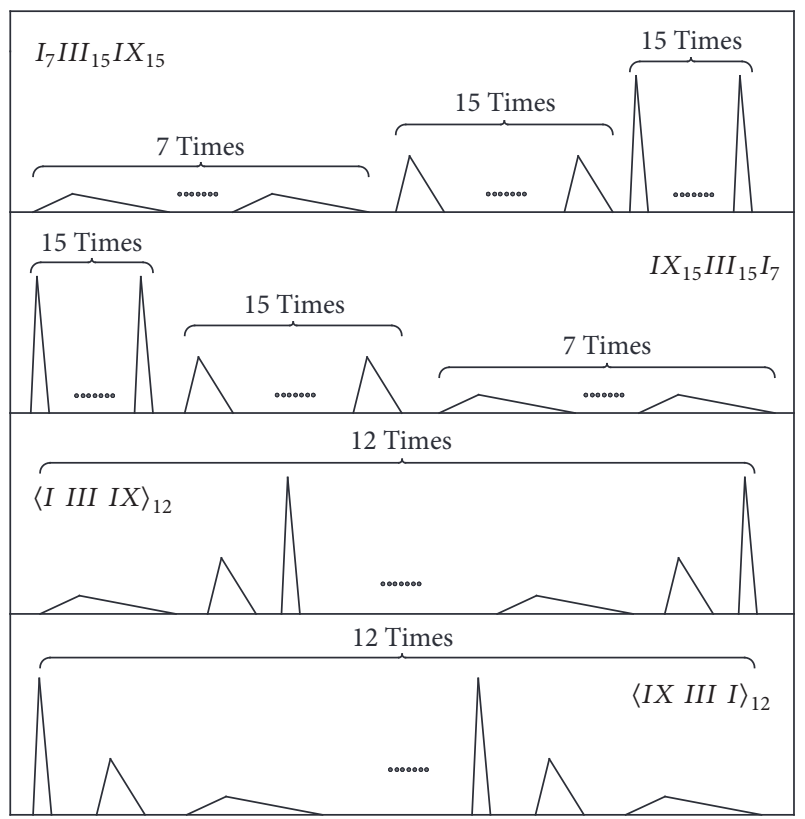

FIGURE 13: Four groups of pressure curves.

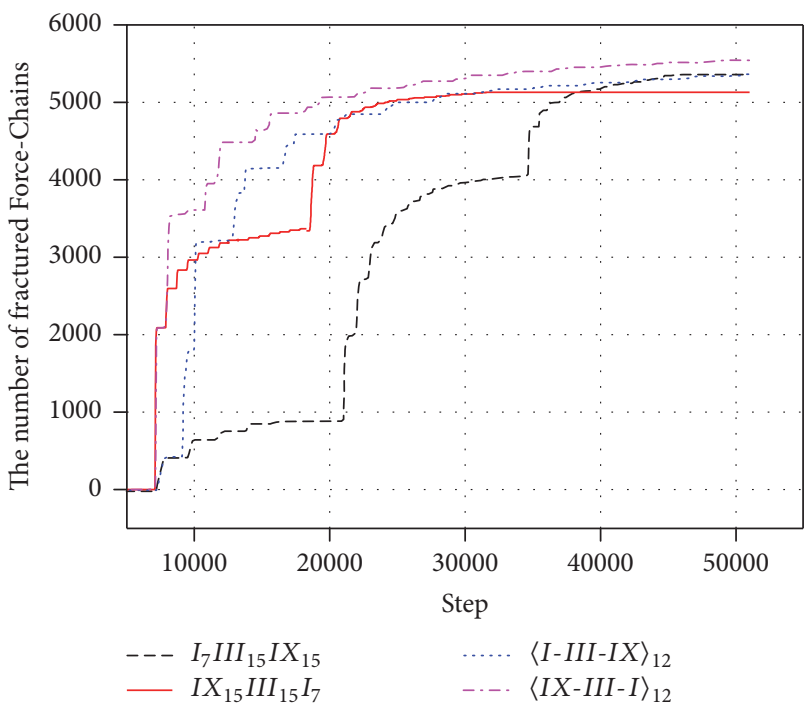

FIGURE 14: Growth curves of fractured Force-Chains under repeated-impacts of HWSWs with different characteristics.

(groups IV-IX), the amount and length of the long cracks had started to decrease, and the range of crack propagation was gradually concentrated to the center of the borehole. Under the single-impact of HWSW, there appears to be an optimal HWSW waveform (groups III), which can achieve the best fracturing effect in a rock mass.

(2) Under the repeated-impacts of HWSWs with same characteristics, the characteristics of fracturing were basically identical to those by a single-impact. Repeated-impacts by HWSWs with same characteristics can strengthen the fracturing effect of a single-impact by corresponding HWSW. Under the repeated-impacts of HWSWs with different characteristics, there was almost no relationship between the fracturing effects and the sequence of repeated-impacts. As long as the characteristics and number of repeatedimpact were definite, the final fracturing effects were basically definite. Under the repeated-impacts of HWSWs, regardless of whether the characteristics of those HWSWs were identical or not, there were limits to crack propagation when the impact times reached a particular number.

(3) Under a single-impact of HWSW with low $P_{P}$ (groups I and III), the initial crack would have better propagation 

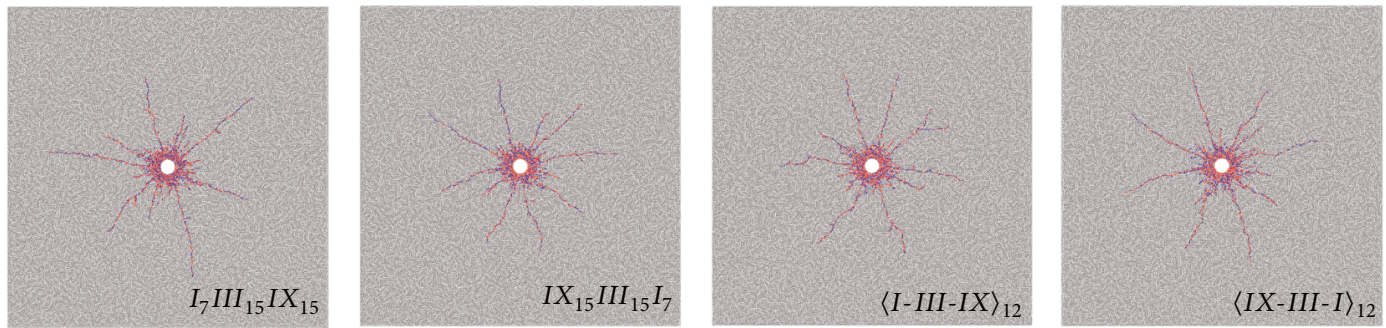

FIGURE 15: Crack propagation under four groups' repeated-impacts of HWSWs with different characteristics.
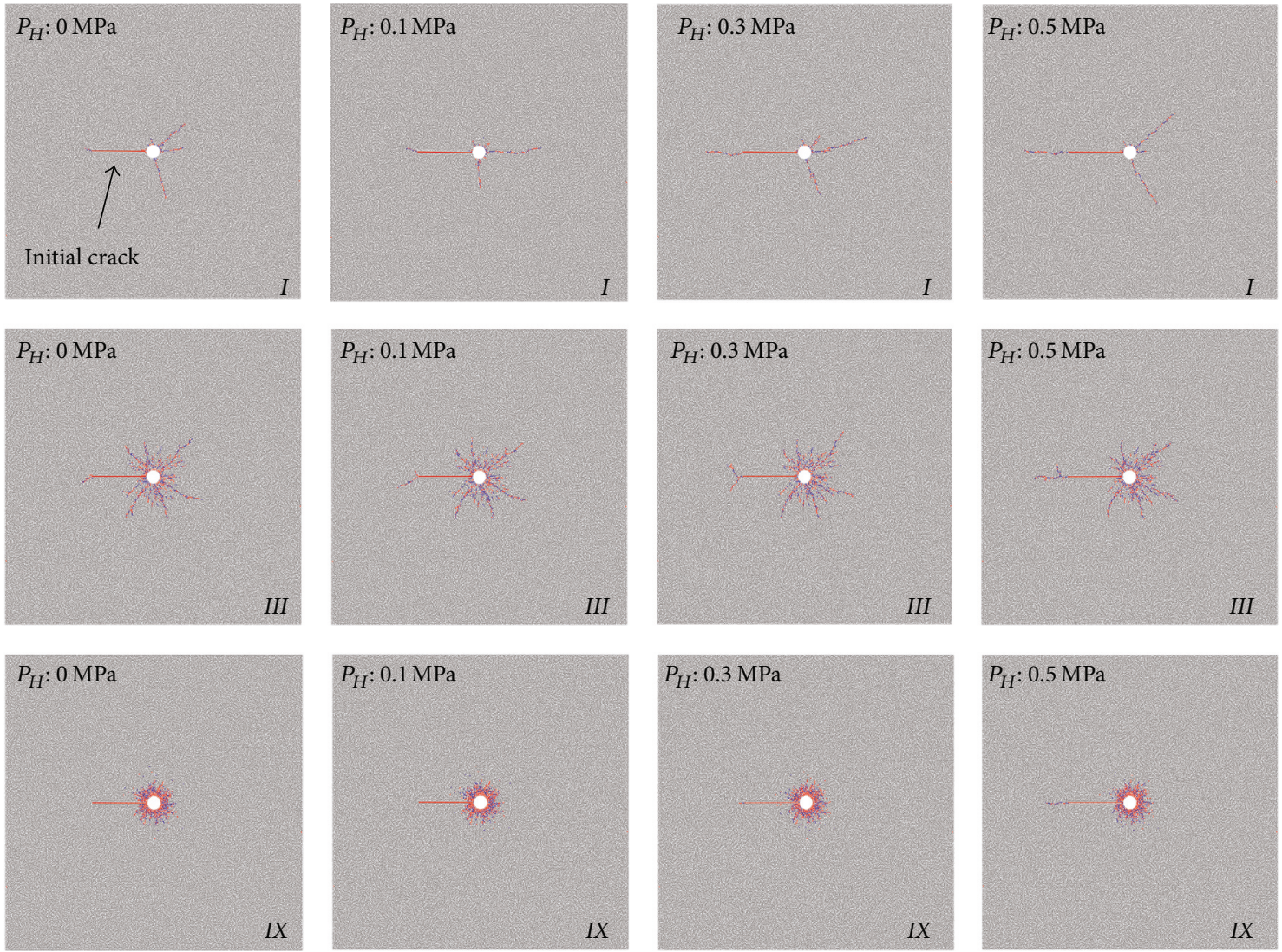

FIGURE 16: Crack propagation under single-impact with $P_{H}$ in initial crack for groups I, III, and IX.

along with an increase in $P_{H}$. Furthermore, microcrack formation near the borehole wall was inhibited (group III). However, when $P_{P}$ of HWSW as too high (group IX), $P_{H}$ was almost no help for increasing crack propagation and had no inhibition effect on microcrack formation.

Additionally, with respect to the hydrostatic numerical simulations in Section 5.4, with different $P_{H}$ affecting the rock, the PFC fracturing model was not adequate to fully understand the fracturing characteristics of a rock sample under repeated-impacts of HWSWs. In the process of rock fracturing by repeated-impacts, $P_{H}$ in cracks can transmit the impact force to the crack tips very well and also effectively prop the fracture. This would greatly promote crack propagation in the PFC model. Besides, when the impact force was transmitted to the crack tips by $P_{H}$, the sequence of repeatedimpacts by different HWSW would have an effect on the final fracturing. Therefore, a fluid-solid coupling dynamic model which conforms to the actual fracturing process needs to be created to accurately perform further research.

\section{Conflicts of Interest}

The authors declare that they have no conflicts of interest.

\section{Acknowledgments}

Financial support for this work was provided by the Natural Science Foundation of China in 2016 (no. 51504220) and the Natural Science Foundation of Shanxi Province in 2017 (no. 201701D121132). The authors would like also to thank the Institute of Coal Mining Technology and North University of 
China for donating the experimental equipment and giving technical support.

\section{References}

[1] W. Chen, O. Maurel, T. Reess et al., "Experimental study on an alternative oil stimulation technique for tight gas reservoirs based on dynamic shock waves generated by pulsed arc electrohydraulic discharges," Journal of Petroleum Science and Engineering, vol. 88-89, pp. 67-74, 2012.

[2] Z. Zhang, Y. Pei, L. Zhen, W. Kuiyang, L. Baohua, and Y. Keping, "Experimental research on rock breakdown under short highvoltage pulse," High Voltage Engineering, vol. 38, no. 7, pp. 17191724, 2012.

[3] Y. Zhang, A. Qiu, H. Zhou, Q. Liu, J. Tang, and M. Liu, "Research progress in electrical explosion shock wave technology for developing fossil energy," High Voltage Engineering, vol. 42, no. 4, pp. 1009-1017, 2016

[4] Y. Qin, A. Qiu, and Y. Zhang, "Experiment and discovery on permeability improved technology of coal reservoir based on repeated strong pulse waves of high energy accumulation," Coal Science and Technology, vol. 42, no. 6, pp. 1-7, 2014.

[5] N. Li, J. G. Huang, K. Z. Lei, J. F. Chen, and Q. F. Zhang, "The characteristic of the bubble generated by underwater highvoltage discharge," Journal of Electrostatics, vol. 69, no. 4, pp. 291-295, 2011.

[6] V. Stelmashuk and P. Hoffer, "Shock waves generated by an electrical discharge on composite electrode immersed in water with different conductivities," IEEE Transactions on Plasma Sciences, vol. 40, no. 7, article A11, pp. 1907-1912, 2012.

[7] H. Zhou, Y. Zhang, H. Li et al., "Generation of electrohydraulic shock waves by plasma-ignited energetic materials: III. Shock wave characteristics with three discharge loads," IEEE Transactions on Plasma Sciences, vol. 43, no. 12, pp. 4017-4023, 2015.

[8] D. Oshita, S. Hosseini, Y. Miyamoto, K. Mawatari, and H. Akiyama, "Study of underwater shock waves and cavitation bubbles generated by pulsed electric discharges," IEEE Transactions on Dielectrics and Electrical Insulation, vol. 20, no. 4, pp. 1273-1278, 2013.

[9] X. P. Lu, Y. Pan, and H. H. Zhang, “The electrical and acoustical characteristics of pulsed discharge in water," Acta Physica Sinica, vol. 51, no. 7, pp. 1549-1553, 2002.

[10] X. Zhou, Y. Qin, H. Li, Y. Zhang, A. Qiu, and Q. Shi, "Formation and development of coal micro-fractures under stress wave induced by electrical impulses," Coal Science and Technology, vol. 43, no. 2, pp. 127-130, 2015.

[11] H. Li, Y. Qin, Y. Zhang, Q. Shi, and X. Zhou, "Experimental study on the effect of strong repetitive pulse shockwave on the pore structure of fat coal," Journal of China Coal Society, vol. 40, no. 4, pp. 915-921, 2015.

[12] O. Maurel, T. Reess, M. Matallah et al., "Electrohydraulic shock wave generation as a means to increase intrinsic permeability of mortar," Cement and Concrete Research, vol. 40, no. 12, pp. 1631-1638, 2010.

[13] S. H. Cho and K. Kaneko, "Influence of the applied pressure waveform on the dynamic fracture processes in rock," International Journal of Rock Mechanics and Mining Sciences, vol. 41, no. 5, pp. 771-784, 2004.

[14] H. Zhang, Z. Chen, and C. Zhang, "Experimental reserches on underwater wire exploding," Explosion and Shock Waves, vol. 22, no. 4, pp. 363-367, 2002.
[15] Z.-L. Li and Q.-Z. Wang, "Experimental research on effect of loading rate for dynamic fracture toughness of rock," Chinese Journal of Geotechnical Engineering, vol. 28, no. 12, pp. 21162120,2006

[16] J. F. Kalthoff and D. A. Shockey, "Instability of cracks under impulse loads," Journal of Applied Physics, vol. 48, no. 3, pp. 986993, 1977.

[17] J. P. VanDevender, "The resistive phase of a high-voltage water spark," Journal of Applied Physics, vol. 49, no. 5, pp. 2616-2620, 1978. 


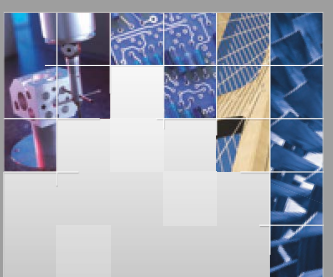

\section{Enfincering}
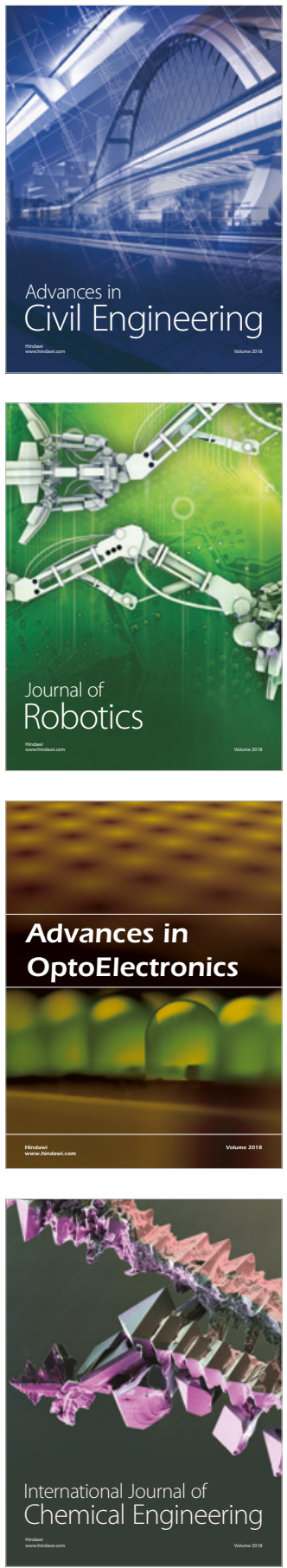

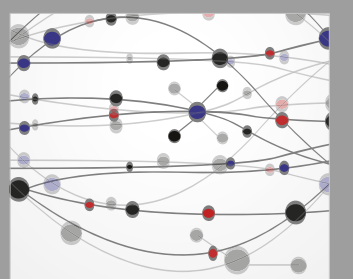

\section{Rotating \\ Machinery}

The Scientific World Journal

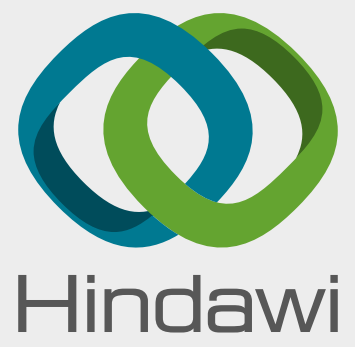

Submit your manuscripts at

www.hindawi.com
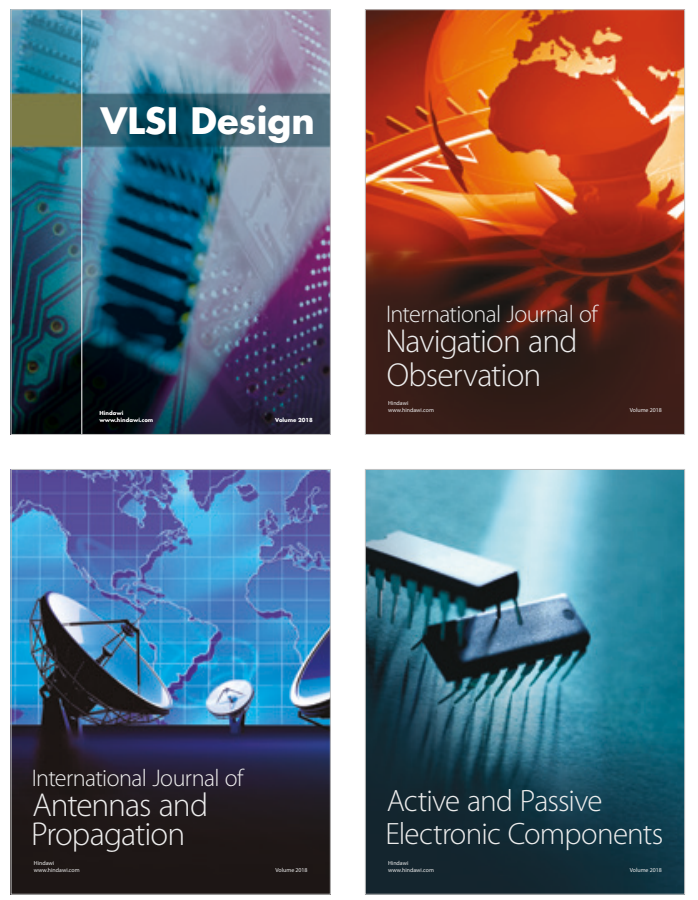
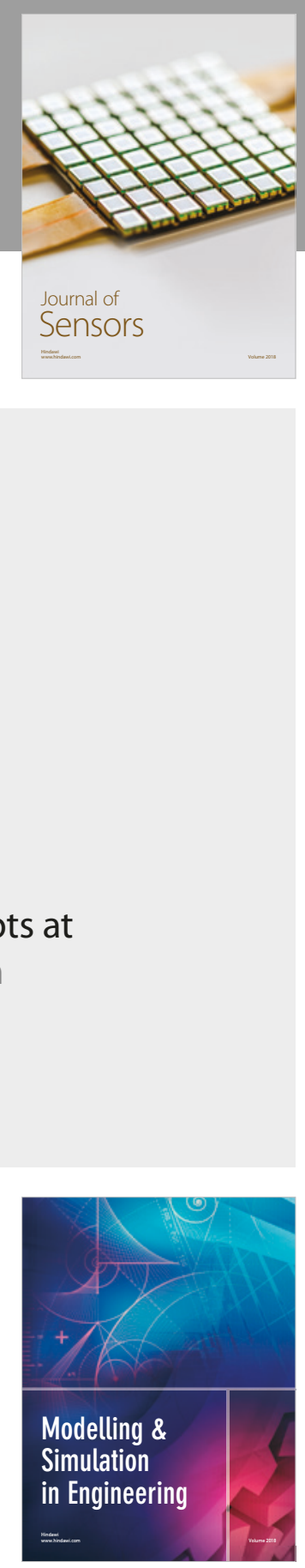

\section{Advances \\ Multimedia}
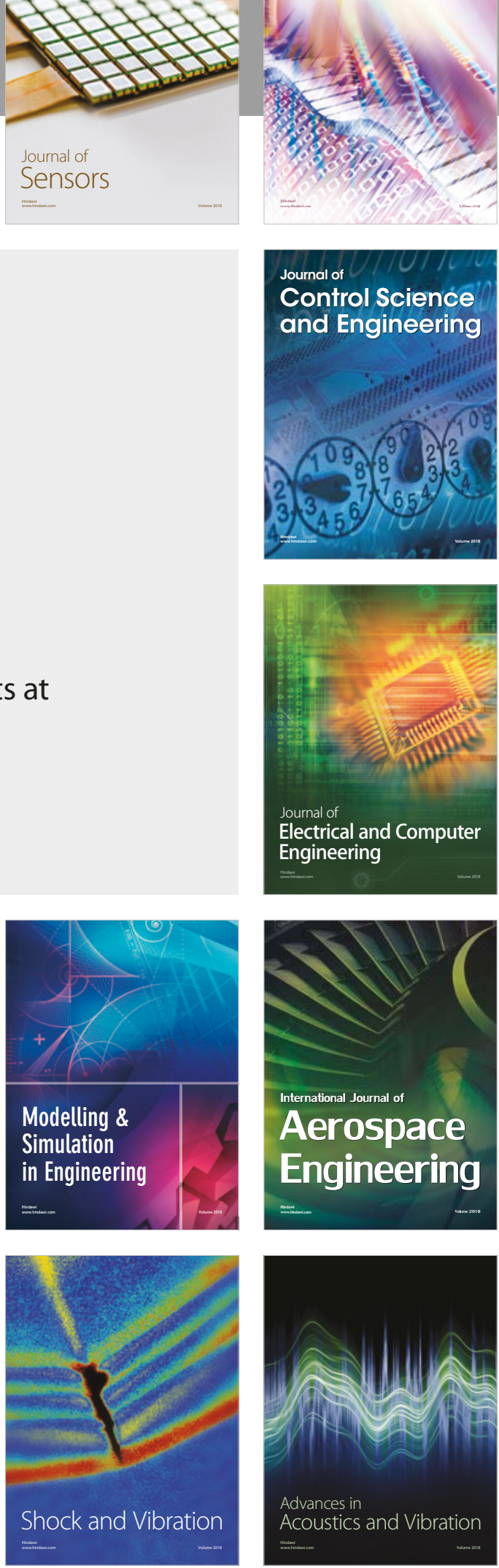